\title{
Genome-wide methylation analysis of tubulocystic and papillary renal cell carcinomas
}

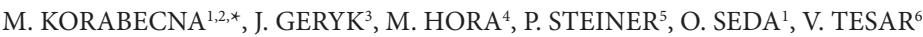 \\ ${ }^{1}$ Institute for Biology and Medical Genetics, First Faculty of Medicine, Charles University in Prague and General University Hospital in Prague, \\ Albertov 4, 12800 Prague, Czech Republic; ${ }^{2}$ Medical Faculty in Pilsen, Charles University in Prague, Husova 3, 30506 Pilsen, Czech Republic; \\ ${ }^{3}$ Central European Biosystems, Prague, Pekarska 603/12, 15500 Prague, Czech Republic; ${ }^{4}$ Department of Urology, Medical Faculty in Pilsen, \\ Charles University in Prague, Dr. E. Benese 13, 30599 Pilsen, Czech Republic; ${ }^{5}$ Bioptic Laboratory, Mikulasske nam. 628/4, 32600 Pilsen, Czech \\ Republic Czech Republic; ${ }^{6}$ Department of Nephrology, First Faculty of Medicine, Charles University in Prague and General University Hospital \\ in Prague, U Nemocnice 2, 12808 Prague, Czech Republic
}

${ }^{*}$ Correspondence: marie.korabecna@lf1.cuni.cz

Received November 2, 2015 / Accepted December 28, 2015

Tubulocystic renal cell carcinoma (TRCC) represents a rare tumor with incidence lower than $1 \%$ of all renal carcinomas. This study was undertaken to contribute to characterization of molecular signatures associated with TRCC and to compare them with the features of papillary renal cell carcinoma (PRCC) at the level of genome wide methylation analysis.

We performed methylated DNA immunoprecipitation (MeDIP) coupled with microarray analysis (Roche NimbleGen). Using the CHARM package, we compared the levels of gene methylation between paired samples of tumors and control renal tissues of each examined individual. We found significant global demethylation in all tumor samples in comparison with adjacent kidney tissues of normal histological appearance but no significant differences in gene methylation between the both compared tumor entities. Therefore we focused on characterization of differentially methylated regions between both tumors and control tissues. We found 42 differentially methylated genes.

Hypermethylated genes for protocadherins $(P C D H G)$ and genes coding for products associated with functions of plasma membrane were evaluated as significantly overrepresented among hypermethylated genes detected in both types of renal cell carcinomas.

In our pilot study, we provide the first evidence that identical features in the process of carcinogenesis leading to TRCC and/or to PRCC may be found at the gene methylation level.

Key words: tubulocystic renal cell carcinoma, papillary renal cell carcinoma, DNA methylation, differentially methylated genes

Tubulocystic renal cell carcinoma (TRCC) represents an entity not yet included in the WHO classification of renal tumors. TRCC has been recognized as a rare renal tumor with male predominance, incidence lower than $1 \%$ of all renal carcinomas [1] and with unique gross and microscopic characteristics unlike other types of renal cell carcinomas. Mostly, such tumors are composed of tubules and cysts lined by a single layer of typical hobnail cells with large nuclei and prominent nucleoli. The literature describing biological behavior, immunohistochemical profiles, ultrastructural features and possible

\footnotetext{
Abbreviations: TRCC - tubulocystic renal cell carcinoma; PRCC - papil-
} lary renal cell carcinoma differential diagnostic features of TRCC is limited [2-6]. Tumor cells show immunohistochemical $\left(\mathrm{CD} 10^{+}, \mathrm{RCC}^{+}\right.$, vimentin ${ }^{+}$, and $\mathrm{AMACR}^{+}$) and ultrastructural (abundant long brush border microvilli) characteristics of proximal renal tubules [1]. The oncogenesis of this neoplasm is unclear. Pathologic and cytogenetic findings seem to document the close relatedness between TRCC and papillary renal cell carcinomas (PRCC) [6]. The close relationship of TRCC to PRCC is supported not only by high frequency of both tumors coexistence but also by expression of proximal convoluted tubule markers (CD10 and AMACR) and by similar chromosomal abnormalities (chromosome 7 and 17 gains and Y chromosome losses)[1]. On the contrary, there are some pieces of evidence against the 
hypothesis claiming the relatedness between TRCC and PRCC like strong diffuse positivity for CK7 observed only in PRCC [7-9] and cytogenetic findings with gains of chromosome 8 and loss of chromosome 9 in TRCC only [10].

Our study was undertaken to contribute to further characterization of molecular signatures associated with such a rare tumor entity as TRCC and to compare them with the features of PRCC at the level of genome wide methylation analysis using MeDIP technology and subsequent comprehensive bioinformatics analysis. We focused namely on the differentially methylated genes in both tumor entities to decipher possible epigenetic events associated with potential disruption of regulatory pathways and leading to tumor development. Methylation of promoter region and transcriptional silencing are well known important mechanisms of gene inactivation. Epigenetic inactivation of $V H L$ gene in renal cell carcinomas belongs to the excellent examples of this phenomenon [11].

Vogelstein et al.[12] determined cancer driver genes $(\sim 140)$ classifiable into 12 signaling pathways. Most solid tumors arise as a consequence of many sequential mutations. Tumors contain 40 - 100 coding gene alterations including 5-15 driver mutations but it has been estimated that each such a mutation provides only very small growth advantage to the affected cell [13]. Epigenetic changes were not studied in the context of general mechanisms of carcinogenesis at the level comparable with mutation analysis in cancer-related genes as summarized by Vogelstein et al. [12]. The study by Beggs et al.[14] demonstrated that in colorectal cancer more than $10 \%$ of protein-coding genes were differentially methylated in comparison with normal colorectal epithelial cells. Similar results were obtained when the clear cell renal carcinomas were compared with adjacent non-tumorous tissues. Deregulation of approximately $7 \%$ genes was explained by epigenetic changes in this case [15].

Hansen et al.[16] studied cancer-specific differentially methylated regions (cDMRs) and found tissue specific chromosomal blocks affected by loss of epigenetic stability mainly by stochastic demethylation varying in individual tumors of the identical type. These hypomethylated blocks in cancer corresponded to more than half of the genome.

With regard to renal carcinogenesis, few studies concerning differential methylation were published using different array platforms $[15,17,18]$ and no study has been focused on alteration of promoter methylation in TRCC.

In our pilot study, we compared molecular signatures associated with TRCC and PRCC at the level of genome wide methylation analysis and we provided the evidence that the process of carcinogenesis leading to tumors of both types has some identical features if examined at the gene methylation level.

\section{Patients and methods}

Recruitment of patients. We analyzed two samples of tubulocystic renal cell carcinomas (TRCC1, TRCC2) and four samples of papillary renal cell carcinomas (PRCC1, PRCC2, PRCC3, PRCC4). Together with all tumor samples their adjacent morphologically normal tissues were analyzed. All samples were retrieved from the Pilsen tumor registry (Bioptic Laboratory, Pilsen, Czech Republic). Tissue samples were originally separated to tumor and non-tumor counterparts and deep-frozen $\left(-80^{\circ} \mathrm{C}\right)$. Clinicopathological characteristics of the analyzed tumors are given in Table 1 . The study was approved by the Local Ethical Committee (LEC) of the Medical Faculty in Pilsen. The process of collection of specimens including inform consent forms was approved by LEC as a part of research project number NT 12010-5/2011 "Assessment of genetic changes in angiogenesis in different subtypes of renal tumors" supported by Internal Grant Agency of the Ministry of Health of the Czech Republic. All participants of the study provided their written informed consents. The documents are recorded at Department of Urology, Medical Faculty in Pilsen belonging to Charles University in Prague.

DNA extraction and processing. For methylation analysis we used frozen samples. DNA from minced tissue was isolated using Nucleospin Tissue kit (Macherey Nagel, Germany) according to the manufacturer's protocols. Isolated DNA was assessed with Nanodrop 1000 spectrophotometer (Thermo Scientific, USA).

$2 \mu \mathrm{g}$ of DNA were treated with anti-5-methylcytosine antibody using MagMeDIP kit (Diagenode, Belgium) according to manufacturer's recommendation. $10 \mathrm{ng}$ of enriched methylated DNA as well as 10\% input DNA were used as an input into whole genome amplification reaction (WGA) using WGA2 - GenomePlex Complete Whole Genome Amplification (WGA) Kit (Sigma-Aldrich, U.S.A.).

$100 \mathrm{ng}$ of amplified DNA was labelled in enzymatic reaction with labeled primers according Nimblegen protocol for DNA methylation analysis (Roche Nimblegen Inc., U.S.A.). The standard protocol includes Cy5 labeling of the test sample and Cy3 labeling of the input sample. The sample was denatured and then incubated for 2 hours at $37^{\circ} \mathrm{C}$ in a thermocycler protected from light with $\mathrm{dNTP} / \mathrm{Klenow}$ Master Mix. The 100 units of Klenow Fragment 3'-5' exo- were used. The reaction was stopped by addition of 0.5M EDTA and the labeled sample was purified using isopropanol precipitation. $15 \mu \mathrm{g}$ of input as well as test sample were mixed, dried and resuspended again in $5.6 \mu \mathrm{l}$ of nuclease free water.

Table 1. Details of examined carcinomas

\begin{tabular}{lllll}
\hline & Tumor ID & Age & Sex & $\begin{array}{l}\text { Tumor size } \\
(\mathbf{c m})\end{array}$ \\
\hline Tubulocystic renal & TRCC1 & 64 & $\mathrm{M}$ & 2.2 \\
cell carcinoma & TRCC2 & 72 & $\mathrm{M}$ & 6.5 \\
Papillary renal cell & PRCC1 & 70 & $\mathrm{M}$ & 9.7 \\
carcinoma & PRCC2 & 38 & $\mathrm{M}$ & 7 \\
& PRCC3 & 79 & $\mathrm{M}$ & 1.5 \\
& PRCC4 & 73 & $\mathrm{~F}$ & 2.5 \\
\hline
\end{tabular}


Methylation array analysis. NimbleGen $3 \times 720 \mathrm{~K} \mathrm{CpG}$ Island Plus RefSeq Promoter Array (Roche Nimblegen Inc., U.S.A.) was used. The hybridization protocol was processed using MAUI Hybridization system (BioMicro, U.S.A.) requiring the adherence of NimbleChip HX3 mixer to the microarray slide. The hybridization master mix solution was prepared using components from a NimbleGen Hybridization Kit, prepared according to the NimbleGen protocol. Hybridization solution and samples were mixed, denatured and loaded into the fill port of a mixer. Then the samples were hybridized for 60 hours at $42^{\circ} \mathrm{C}$ in the mix mode $\mathrm{B}$.

Posthybridization washing was done using Nimblegen buffers with increasing stringency (Roche NimbleGen, U.S.A.)

Microarrays were scanned with InnoScan 900 (Innopsys, France) at $2 \mu \mathrm{m}$ resolution. Image analysis was performed in NimbleScan 2.6 software (Roche NimbleGen, U.S.A.) according to appropriate .ndf file.

We use the CHARM package $[19,20]$ to normalize data and to find differentially methylated regions (DMRs) and genes between studied groups. The CHARM package implements normalization procedure well suited for methylation arrays. The within-sample normalization is based on selecting $\mathrm{CpG}$-free probes to represent signal from unmethylated regions. The Loess regression is fitted to these $\mathrm{CpG}$-free probes and the resulting correction curve is applied to remaining probes. The between-sample normalization is based on subset quantile normalization, where the subset is represented by negative, non-CpG- free probes. The CHARM package integrates all normalization procedures together with batch effects correction and Bayesian percentage methylation estimates into one function (methp). After applying methp function, we obtained normalized estimates of proportional methylation of individual probes. As the last correction step, the probes with quality index $<75$ were removed. All subsequent analyses within CHARM package were performed on the percentage methylation estimates obtained by methp function. Clustering of samples was performed by function cmdsplot within CHARM package. Results of cluster analysis were visualized on two-dimensional plot allowing visual accession of the separation between groups. DMRs were identified by function dmrFind. Function dmrFind identifies genomic intervals with significantly different average methylation between studied groups of samples. The important parameter produced by this function is average percentage methylation difference (avg). avg is simply the difference between average proportional methylation of all probes associated with specific DMR within control samples and tumor samples. Subsequently, function qval was applied in order to obtain significance estimates of individual DMRs. The significance of individual DMR is computed by randomization procedure as a false discovery rate and it is denoted as q-value. Significant DMRs were annotated by genomic features such as transcription start sites or $\mathrm{CpG}$ islands. The gene set associated with specific DMR was obtained as a list of all genes having their transcription start site within the DMR. The selected gene sets were analyzed using the Database for Annotation, Visualization and Integrated Discovery (DAVID) [21] by the functional annotation clustering with

Table 2. Differentially methylated genes - comparison between tumor group (containing both PRCC and TRCC) and control kidney tissues of normal histological appearance

\begin{tabular}{|c|c|c|c|}
\hline \multicolumn{4}{|c|}{ Genes hypermethylated in tumors } \\
\hline Gene Name & Gene Description & $\begin{array}{l}\text { Average percentage } \\
\text { methylation } \\
\text { difference }\end{array}$ & $\begin{array}{l}\text { q-value } \\
\text { (for associated } \\
\text { DMR) }\end{array}$ \\
\hline ANKLE2 & ankyrin repeat and LEM domain containing 2 & -0.1800 & 0.0200 \\
\hline KATNAL2 & katanin p60 subunit A-like 2 & -0.3605 & 0.0238 \\
\hline HPS4 & Hermansky-Pudlak syndrome 4 & -0.3367 & 0.0313 \\
\hline STARD13 & STAR-related lipid transfer (START) domain containing 13 & -0.1982 & 0.0325 \\
\hline PCDHG genes & $\begin{array}{l}\text { protocadherin gamma subfamily: } P C D H G A 1, P C D H G A 2 \text { PCDHGA3, PCDHGB1, PCDHGA4, } \\
P C D H G B 2, P C D H G A 5, P C D H G B 3, P C D H G A 6, P C D H G A 7, P C D H G B 4, P C D H G A 8, P C D H G B 5 \text {, } \\
P C D H G A 9, P C D H G B 6, P C D H G A 10, P C D H G B 7, P C D H G A 11, P C D H G A 12\end{array}$ & -0.2447 & 0.0363 \\
\hline OSR1 & odd-skipped related 1 (Drosophila) & -0.2264 & 0.0377 \\
\hline GNAS & GNAS complex locus & -0.1786 & 0.0386 \\
\hline SLC20A2 & solute carrier family 20 (phosphate transporter), member 2 & -0.2452 & 0.0415 \\
\hline ANKS1B & ankyrin repeat and sterile alpha motif domain containing $1 \mathrm{~B}$ & -0.1652 & 0.0417 \\
\hline ARHGEF7 & Rho guanine nucleotide exchange factor (GEF) 7 & -0.1949 & 0.0437 \\
\hline FBXO18 & F-box protein, helicase, 18 & -0.2652 & 0.0438 \\
\hline SNORA2B & small nucleolar RNA, H/ACA box 2B & -0.1826 & 0.0440 \\
\hline KCTD1 & potassium channel tetramerisation domain containing 1 & -0.2833 & 0.0442 \\
\hline KBTBD4 & kelch repeat and $\mathrm{BTB}$ (POZ) domain containing 4 & -0.1998 & 0.0475 \\
\hline TTC13 & tetratricopeptide repeat domain 13 & -0.1859 & 0.0494 \\
\hline LNPEP & leucyl/cystinyl aminopeptidase & -0.1711 & 0.0497 \\
\hline
\end{tabular}


medium classification stringency and with calculation of Bonferroni and Benjamini corrections and false discovery rates (FDR).

In order to study global hypomethylation, we applied only the within-sample normalization implemented within CHARM package without the between-sample normalization because the between-sample normalization erases global differences between samples which we wanted to find [22]. After the within-sample normalization, we made a separate plot for every pair of tumor and control adjacent tissue. Densities of probe $\mathrm{M}$-values from one tumor sample (dashed line) and from paired control tissue (solid line) were drawn on every plot. We then repeated the analysis with probes associated with $\mathrm{CpG}$ islands - the same plots type as in previous case were produced.

\section{Results}

The raw data for each examined entity are available in Array Express database (Experiment name: Genome-wide methylation analysis of tubulocystic and papillary renal cell carcinomas, Array Express accession: E-MTAB-2829, specified release date: 2016-01-15).

Fig 1 and 2 demonstrate whole genome and CpG islands hypomethylation in all tumor samples in comparison with their control kidney tissues of normal histological appearance.
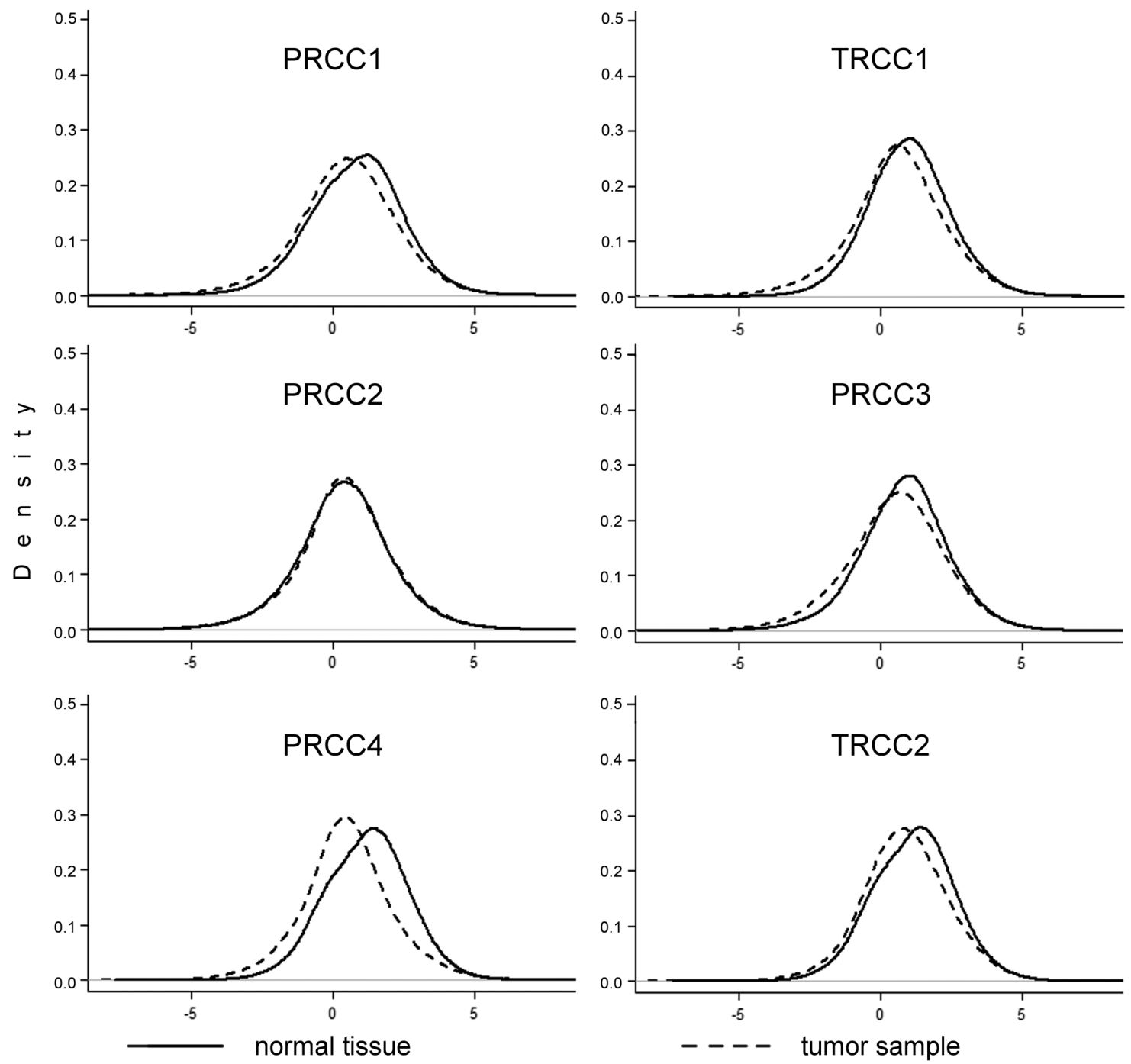

M - v a I u e s

Figure 1. Whole genome hypomethylation in all examined tumor tissues. Density ( $\mathrm{y}$-axis) of probe M-values ( $\mathrm{x}$-axis) from tumor sample is plotted as dashed line and density of probe $M$-values from paired normal tissue sample is plotted as solid line for each pair of tumor and paired adjacent normal tissue 
We obtain very similar results (global hypomethylation) by applying vsn normalization to raw data and subsequently hidden Markov chain procedure configured to classify genomic intervals into three states: hypomethylated, non-changed and hypermethylated.

The analysis performed using the CHARM package did not reveal any significant differences at the gene methylation level between the compared tumor samples (TRCC versus PRCC). Due to this fact, we focused on the search for differentially methylated genes between the group containing both tumors and the group of control tissues with the goal to characterize the features shared by both tumor entities keeping in mind that the results obtained by cluster analysis do not suggest that the methylation profiles of both types of tumors are fully identi- cal (Fig 3). Cluster analysis compares the whole methylation profiles of samples mutually taking in account also the nonsignificant differences among analyzed samples.

Using CHARM package, we selected the set of genes differentially methylated in both tumor entities and kidney tissues of normal histological appearance. The genes together with their average percentage methylation difference and q- values are given in Tables 2 and 3.

The genes listed in Table 2 were analyzed using the Database for Annotation, Visualization and Integrated Discovery (DAVID) by the functional annotation clustering with medium classification stringency and with calculations of Benjamini and/or Bonferroni corrections and false discovery rates (FDR).
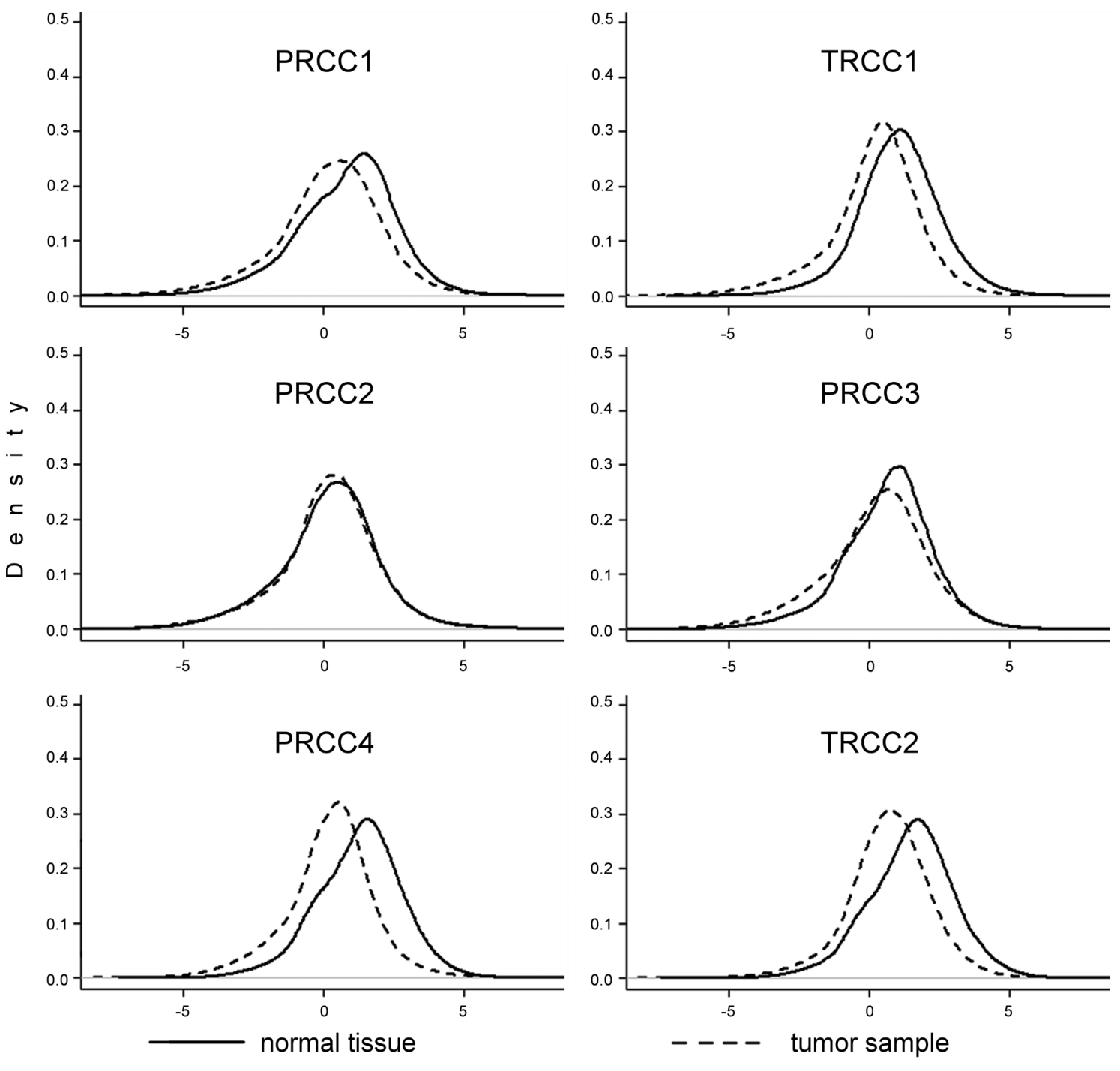

M-values

Figure 2. $\mathrm{CpG}$ islands hypomethylation in all examined tumor tissues. Density ( $\mathrm{y}$-axis) of probe $\mathrm{M}$-values ( $\mathrm{x}$-axis) from tumor sample is plotted as dashed line and density of probe $\mathrm{M}$-values from paired normal tissue sample is plotted as solid line for each pair of tumor and paired adjacent normal tissue. 
Using this approach the cluster containing the group of 19 genes for protocadherins gamma was discovered with high statistical significance $\left(\mathrm{p}\right.$ value $=1.2 \times 10^{-49}$ after Bonferroni and/or Benjamini corrections, FDR $=2.5 \times 10^{-48}$ ). Functional annotation clustering applied on the set of genes listed in Table 2 revealed also other significantly overrepresented genes associated with the plasma membrane functions (Table 4).

\section{Discussion}

We observed striking global demethylation in all examined tumors as documented in Fig 1 and 2. Global DNA hypomethylation in tumors belongs to the well described phenomenon. It has been reported earlier than cancer associated DNA hypermethylation [23]. It is thought that the global loss of DNA methylation in cancer is associated with chromosomal instability, reactivation of transposable elements and loss of imprinting [24].

Such a DNA hypomethylation in cancer often affects larger part of the genome than promoter-specific DNA hypermethylation which disables namely tumor suppressor genes and their functions in cell cycle regulation. In contrast to transcriptional silencing of tumor suppressor genes through promoter hypermethylation, hypomethylation dependent transcriptional activation in cancer is less frequent [24]. Hansen et al. [16] documents the hypomethylation of chromosomal blocks corresponding to more than half of the genome in cancer tissues.

Among hypermethylated genes in both examined tumor entities, we found the prominent group of 19 genes for protocadherins gamma (PCDHG). Molecular mechanisms that could explain the relation between methylation of PCDHG gene sequences and cancer remain to be better elucidated. In most studies analyzing DNA methylation in renal cancer, the methylation of these genes was not reported [www.pubmeth. org, $[17,18]$. The PCDGH genes were also not mentioned as methylated in normal tissues [25]. The study focused on carcinogenesis of Wilms' tumors reported epigenetic silencing of protocadherin genes caused by DNA hypermethylation

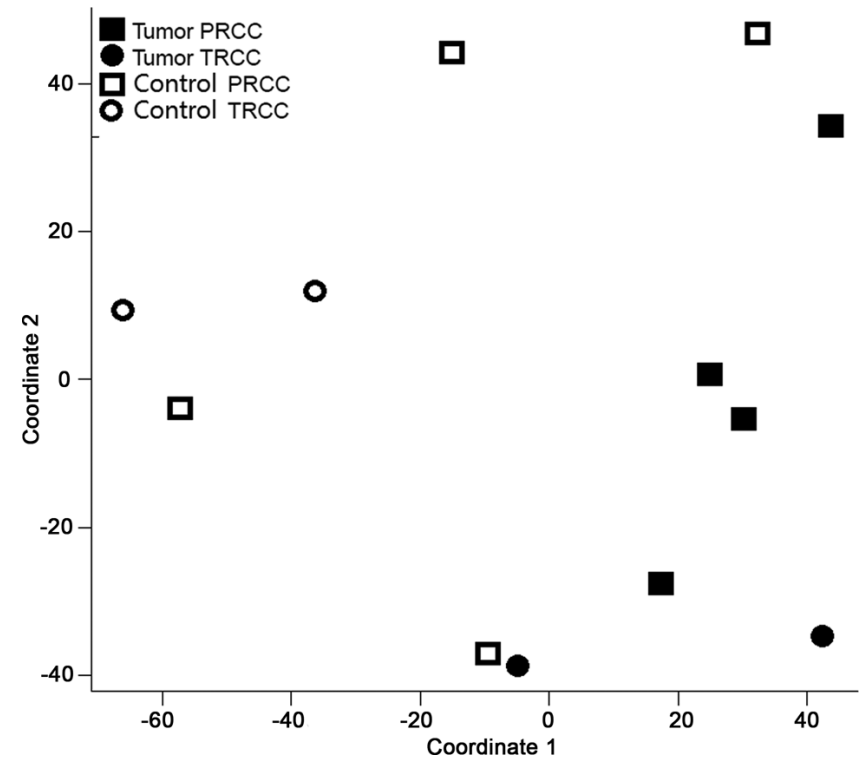

Figure 3. Results of cluster analysis performed by function cmdsplot within CHARM package. For cluster analysis, the 400,000 most variable probes out of 678,912 total were used, probes on sex chromosomes were not included into analysis.

as concordant with decreased expression of protocadherins in tumors. The authors provided data implicating the role of PCDHGA encoded proteins in negative modulation of canonical Wnt signaling in kidney [26]. Recent studies demonstrated that the genes for protocadherins may act as tumor suppressor genes and that the inactivation of their promoters correlates with tumor development [27]. The gene PCDHGA11 which is included in our list has been found to be inactivated by promoter hypermethylation in astrocytomas and glioblastomas [28]. Similarly, the hypermethylations of PCDHGA10 and $P C D H G A 8$ were found in numerous cancer and cancer cell lines [27].

Our analysis performed using DAVID on the set of genes significantly hypermethylated in both tumors revealed also

Table 3. Differentially methylated genes - comparison between tumor group (containing both PRCC and TRCC) and control kidney tissues of normal histological appearance

\begin{tabular}{llcc}
\hline Genes hypomethylated in tumors & \\
\hline Gene Name & Gene Description & $\begin{array}{c}\text { Average percentage } \\
\text { methylation difference }\end{array}$ & $\begin{array}{c}\text { q-value } \\
\text { (for associated DMR) }\end{array}$ \\
\hline CAMKK1 & calcium/calmodulin-dependent protein kinase kinase 1, alpha & 0.2752 & 0.0150 \\
RAB11FIP3 & RAB11 family interacting protein 3 (class II) & 0.2532 & 0.0217 \\
CHDH & choline dehydrogenase & 0.20361 & 0.0342 \\
SRC & v-src sarcoma (Schmidt-Ruppin A-2) viral oncogene homolog (avian) & 0.1884 & 0.0366 \\
LMNB2 & lamin B2 & 0.2293 & 0.0402 \\
SERPINA1 & serpin peptidase inhibitor, clade A (alpha-1 antiproteinase, antitrypsin), member 1 & 0.2277 & 0.0402 \\
HRH1 & histamine receptor H1 & 0.2281 & 0.0444 \\
CLDN10 & claudin 10 & 0.1870 & 0.0499 \\
\hline
\end{tabular}


Table 4. Top terms identified by DAVID for hypermethylated genes found in both tumors

\begin{tabular}{|c|c|c|c|c|}
\hline Term & Official gene symbols & $\begin{array}{l}\text { p-value after Benjamini } \\
\text { correction }\end{array}$ & No. of genes & FDR \\
\hline $\begin{array}{l}\text { Protocadherin gamma } \\
\text { (INTERPRO) }\end{array}$ & $\begin{array}{l}\text { PCDHGA 1, PCDHGA2, PCDHGA3, PCDHGA4, } \\
\text { PCDHGA5, PCDHGA6, PCDHGA7, PCDHGA8, } \\
\text { PCDHGA9, PCDHGA10, PCDHGA11, PCDHGA12, } \\
\text { PCDHGB1, PCDHGB2, PCDHGB3, PCDHGB4, PCDHGB5, } \\
\text { PCDHGB6, PCDHGB7 (further as PCDHG genes) }\end{array}$ & $1.2 \times 10^{-49}$ & 19 & $2.5 \times 10^{-48}$ \\
\hline $\begin{array}{l}\text { Homophilic cell adhesion } \\
\text { (GO TERM FAT) }\end{array}$ & PCDHG genes & $3.8 \times 10^{-29}$ & 19 & $2.9 \times 10^{-28}$ \\
\hline $\begin{array}{l}\text { Cell- cell adhesion } \\
\text { (GO TERM FAT) }\end{array}$ & $P C D H G$ genes & $3.2 \times 10^{-16}$ & 19 & $7.1 \times 10^{-15}$ \\
\hline $\begin{array}{l}\text { Calcium binding } \\
\text { (GO TERM FAT) }\end{array}$ & $P C D H G$ genes & $7.9 \times 10^{-13}$ & 19 & $1.2 \times 10^{-11}$ \\
\hline $\begin{array}{l}\text { Cell membrane } \\
\text { (GO TERM FAT) }\end{array}$ & $\begin{array}{l}\text { ANKS1B, ARHGEF7, GNAS, PCDHG genes, LNPEP, } \\
\text { SLC20A2 }\end{array}$ & $4.5 \times 10^{-14}$ & 24 & $2.0 \times 10^{-12}$ \\
\hline $\begin{array}{l}\text { Plasma membrane } \\
\text { (GO TERM CC) }\end{array}$ & $\begin{array}{l}\text { ANKS1B, ARHGEF7, GNAS, KCTD1, LNPEP, PCDHG } \\
\text { genes, STARD13, SLC20A2 }\end{array}$ & $2.6 \times 10^{-8}$ & 26 & $3.6 \times 10^{-7}$ \\
\hline $\begin{array}{l}\text { Metal ion binding } \\
\text { (GO TERM MF FAT) }\end{array}$ & LNPEP, PCDHG genes, OSR1, SLC20A2 & $1.2 \times 10^{-4}$ & 22 & $3.6 \times 10^{-3}$ \\
\hline $\begin{array}{l}\text { Intrinsic to membrane } \\
\text { (GO TERM CC FAT) }\end{array}$ & $\begin{array}{l}\text { ANKS1B, GNAS, KCTD1, LNPEP, PCDHG genes, } \\
\text { SLC20A2 }\end{array}$ & $2.6 \times 10^{-3}$ & 24 & $7.3 \times 10^{-2}$ \\
\hline
\end{tabular}

statistically significant overrepresentation of genes whose products are associated with plasma membrane functions (Table 4). One of these genes - STARD13 - codes for GTPaseactivating protein for RhoA. Its product may be involved in regulation of cytoskeletal reorganization, cell proliferation and cell motility. STARD13 is ubiquitously expressed and it acts as a tumor suppressor in hepatocellular carcinoma cells [29].

Product of the gene LNPEP is the leucyl/cystinyl aminopeptidase (vasopressinase) which cleaves vasopressin (antidiuretic hormone). Vasopressin regulates the body's retention of water through increased water reabsorbtion in the collecting ducts of kidney nephron [30].

The gene SLC20A2 encodes sodium-phosphate symporter which play a fundamental housekeeping role in phosphate transport by absorbing phosphate from interstitial fluid. It is crucial for normal cellular functions such as cellular metabolism, signal transduction, and nucleic acid and lipid synthesis [31].

Our analysis of hypermethylated genes highlighted the role of epigenetic deregulation of genes encoding proteins associated with the physiological functions of plasma membrane in kidney in the carcinogenesis of both tumors studied by us.

Among genes that were detected as significantly hypomethylated in TRCC and PRCC tumors, we found SERPINA1 (serpin peptidase inhibitor clade A member 1). The expression of SERPINA1 plays the role in the invasion and migration of gastric cancer cells and it is associated with the progression of gastric cancer [32] .

The gene CAMKK1 (encoding calcium/calmodulindependent protein kinase 1) has been found also as hypomethylated in both types of tumors. Constitutive activation of CAMKK1 was reported as sufficient for mTORC1 activation in an experimental system [33]. The involvement of mTORC1 signaling pathway in renal carcinogenesis is well known [34].

Above listed selected functions of epigenetically deregulated genes found by us in TRCC and PRCC are not only in good agreement with recent knowledge about general aspects of carcinogenesis but they provide also new point of view on development of both tumor entities stressing the role of altered cell membrane physiological functions in renal carcinogenesis leading to papillary and/or tubulocystic carcinomas.

With regard to recent knowledge about the mechanisms of epigenetic deregulation in cancer [16], it seems that the significant differences in methylation patterns between two tumor types often appearing simultaneously in the same tissue could be hardly detectable due to the existence of tissue specific chromosomal blocks with highly variable methylation even among the samples of the identical tumor type. In our pilot study, we selected genes which could attract further attention of researcher due to their potential roles in renal carcinogenesis generally rather than as markers for specific renal cancer types.

We found 42 differentially methylated genes between both tumor and control tissues. Hypermethylated genes for protocadherins $(P C D H G)$ and genes coding for products associated with functions of plasma membrane (e.g. ANKS1B, ARHGEF7, GNAS, KCTD1, LNPEP, STARD13, SLC20A2) were evaluated as significantly overrepresented among hypermethylated genes detected in both types of tumors. Our findings highlighted 
the importance of gene products associated with plasma membrane in renal oncogenesis leading to TRCC and/or PRCC and they provided further evidence for close molecular relationship between the examined tumors. The functions of potentially epigenetically deregulated genes detected by us in the both tumors are in good agreement with the known facts about general carcinogenesis but they should be examined in more complex further studies focused on cancer development in kidneys.

Acknowledgments: Supported by the grant no. PRVOUK P25/ LF1/2 of the Ministry of Education, Youth and Sport of the Czech Republic, by the grant no. RVO-VFN 64165 of the Ministry of Health of the Czech Republic, by the grant TIP I/328 of the Ministry of Industry and Trade of the Czech Republic, and by the grant no. NT 12010-5/2011 of the Ministry of Health of the Czech Republic.

\section{References}

1[1] ALEXIEV BA, DRACHENBERG CB Tubulocystic carcinoma of the kidney: a histologic, immunohistochemical, and ultrastructural study. Virchows Arch 2013; 462: 575-581. http:// dx.doi.org/10.1007/s00428-013-1398-0

[2] AZOULAY S, VIEILLEFOND A, PARAF F, PASQUIER D, CUSSENOT O et al. Tubulocystic carcinoma of the kidney: a new entity among renal tumors. Virchows Arch 2007; 451: 905-909. http://dx.doi.org/10.1007/s00428-007-0483-7

[3] YANG XJ, ZHOU M, HES O, SHEN S, LI R et al. Tubulocystic carcinoma of the kidney: clinicopathologic and molecular characterization. Am J Surg Pathol. 2008; 32: 177-187. http:// dx.doi.org/10.1097/PAS.0b013e318150df1d

[4] AMIN MB, MACLENNAN GT, GUPTA R, GRIGNON D, PARAF F et al. Tubulocystic carcinoma of the kidney: clinicopathologic analysis of 31 cases of a distinctive rare subtype of renal cell carcinoma. Am J Surg Pathol 2009; 33: 384-392. http://dx.doi.org/10.1097/PAS.0b013e3181872d3f

[5] OSUNKOYA AO, YOUNG AN, WANG W, NETTO GJ, EPSTEIN JI Comparison of gene expression profiles in tubulocystic carcinoma and collecting duct carcinoma of the kidney. Am J Surg Pathol 2009; 33: 1103-1106. http://dx.doi. org/10.1097/PAS.0b013e3181a13e7b

[6] BHULLAR JS, VARSHNEY N, BHULLAR AK, MITTAL VK A new type of renal cancer-tubulocystic carcinoma of the kidney: A review of the literature. Int J Surg Pathol 2014; 22: 297-302. http://dx.doi.org/10.1177/1066896913509007

[7] ZHOU M, ROMA A, MAGI-GALLUZZI C The usefulness of immunohistochemical markers in the differential diagnosis of renal neoplasms. Clin Lab Med 2005; 25: 247-257. http:// dx.doi.org/10.1016/j.cll.2005.01.004

[8] ROSS H, MARTIGNONI G, ARGANI P Renal cell carcinoma with clear cell and papillary features. Arch Pathol Lab Med 2012; 136: 391-399. http://dx.doi.org/10.5858/arpa.2011-0479 $\underline{-\mathrm{RA}}$

[9] BHATNAGAR R, ALEXIEV BA Renal-cell carcinomas in endstage kidneys: a clinicopathological study with emphasis on clear-cell papillary renal-cell carcinoma and acquired cystic kidney disease-associated carcinoma. Int J Surg Pathol 2012; 20: 19-28. http://dx.doi.org/10.1177/1066896911414273

[10] QUIROGA-GARZA G, PINA-OVIEDO S, CUEVAS-OCAMPO K, GOLDFARB R, SCHWARTZ MR et al. Synchronous clear cell renal cell carcinoma and tubulocystic carcinoma: genetic evidence of independent ontogenesis and implications of chromosomal imbalances in tumor progression. Diagn Pathol 2012; 7: 21. http://dx.doi.org/10.1186/1746-1596-7$\underline{21}$

[11] MORRIS MR, RICKETTS CJ, GENTLE D, MCRONALD F, CARLI N et al. Genome-wide methylation analysis identifies epigenetically inactivated candidate tumour suppressor genes in renal cell carcinoma. Oncogene. 2011; 30: 1390-1401. http://dx.doi.org/10.1038/onc.2010.525

[12] VOGELSTEIN B, PAPADOPOULOS N, VELCULESCU VE, ZHOU S, DIAZ LA er al. Cancer genome landscapes. Science. 2013; 339: 1546-1558. http://dx.doi.org/10.1126/ science. 1235122

[13] BOZIC I, ANTAL T, OHTSUKI H, CARTER H, KIM D et al. Accumulation of driver and passenger mutations during tumor progression. Proc Natl Acad Sci U S A 2010; 107: 18545-18550. http://dx.doi.org/10.1073/pnas.1010978107

[14] BEGGS AD, JONES A, EL-BAHRAWY M, ABULAFI M, HODGSON SV et al. Whole-genome methylation analysis of benign and malignant colorectal tumours. J Pathol 2013; 229: 697-704. http://dx.doi.org/10.1002/path.4132

[15] WOZNIAK MB, LE CALVEZ-KELM F, ABEDI-ARDEKANI B, BYRNES G, DURAND G et al. Integrative genome-wide gene expression profiling of clear cell renal cell carcinoma in Czech Republic and in the United States. PLoS One 2013; 8: e57886. http://dx.doi.org/10.1371/journal.pone.0057886

[16] HANSEN KD, TIMP W, BRAVO HC, SABUNCIYAN S, LANGMEAD B et al. Increased methylation variation in epigenetic domains across cancer types. Nat Genet 2011; 43: 768-775. http://dx.doi.org/10.1038/ng.865

[17] RICKETTS CJ, MORRIS MR, GENTLE D, BROWN M, WAKE $\mathrm{N}$ et al. Genome-wide CpG island methylation analysis implicates novel genes in the pathogenesis of renal cell carcinoma. Epigenetics 2012; 7: 278-290. http://dx.doi. org/10.4161/epi.7.3.19103

[18] ARAI E, KANAI Y Genetic and epigenetic alterations during renal carcinogenesis. Int J Clin Exp Pathol 2010; 4: 58-73.

[19] YALCIN A, KREUTZ C, PFEIFER D, ABDELKARIM M, KLAUS G et al. MeDIP coupled with a promoter tiling array as a platform to investigate global DNA methylation patterns in AML cells. Leuk Res 2013; 37: 102-111. http://dx.doi. org/10.1016/j.leukres.2012.09.014

[20] IRIZARRY RA, LADD-ACOSTA C, CARVALHO B, WU H, BRANDENBURG SA et al. Comprehensive high-throughput arrays for relative methylation (CHARM). Genome Res 2008; 18: 780-790. http://dx.doi.org/10.1101/gr.7301508

[21] HUANG DA W, SHERMAN BT, LEMPICKI RA Bioinformatics enrichment tools: paths toward the comprehensive functional analysis of large gene lists. Nucleic Acids Res 2009; 37: 1-13. http://dx.doi.org/10.1093/nar/gkn923

[22] ARYEE MJ, WU Z, LADD-ACOSTA C, HERB B, FEINBERG AP et al. Accurate genome-scale percentage DNA 
methylation estimates from microarray data. Biostatistics 2011; 12: 197-210. http://dx.doi.org/10.1093/biostatistics/ $\underline{\mathrm{kxq} 055}$

[23] FEINBERG AP, VOGELSTEIN B Hypomethylation distinguishes genes of some human cancers from their normal counterparts. Nature 1983; 301: 89-92. http://dx.doi. org/10.1038/301089a0

[24] TORANO EG, PETRUS S, FERNANDEZ AF, FRAGA MF Global DNA hypomethylation in cancer: review of validated methods and clinical significance. Clin Chem Lab Med 2012; 50: 1733-1742. http://dx.doi.org/10.1515/cclm-2011-0902

[25] FERNANDEZ AF, ASSENOV Y, MARTIN-SUBERO JI, BALINT B, SIEBERT R et al. A DNA methylation fingerprint of 1628 human samples. Genome Res 2012; 22: 407-419. http:// dx.doi.org/10.1101/gr.119867.110

[26] DALLOSSO AR, HANCOCK AL, SZEMES M, MOORWOOD K, CHILUKAMARRI L et al. Frequent long-range epigenetic silencing of protocadherin gene clusters on chromosome 5q31 in Wilms' tumor. PLoS Genet 2009; 5: e1000745. http://dx.doi.org/10.1371/journal.pgen.1000745

[27] SUI XB, WANG D, GENG SM, ZHOU GL, HE C et al. Methylated promoters of genes encoding protocadherins as a new cancer biomarker family. Mol Biol Rep 2012; 39: 1105-1111. http://dx.doi.org/10.1007/s11033-011-0837-8

[28] WAHA A, GUNTNER S, HUANG THM, YAN PS, ARSLAN $B$ et al. Epigenetic silencing of the protocadherin family member PCDH-gamma-A11 in astrocytomas. Neoplasia 2005; 7: 193-199. http://dx.doi.org/10.1593/neo.04490
[29] EL-SITT S, EL-SIBAI M The STAR of the DLC family. J Recept Signal Transduct Res 2013; 33: 10-13. http://dx.doi. org/10.3109/10799893.2012.752002

[30] NIELSEN S, CHOU CL, MARPLES D, CHRISTENSEN EI, KISHORE BK et al. Vasopressin increases water permeability of kidney collecting duct by inducing translocation of aquaporin-CD water channels to plasma membrane. Proc Natl Acad Sci U S A 1995; 92: 1013-1017. http://dx.doi. org/10.1073/pnas.92.4.1013

[31] VILLA-BELLOSTA R, RAVERA S, SORRIBAS V, STANGE G, LEVI M et al. The Na+-Pi cotransporter PiT-2 (SLC20A2) is expressed in the apical membrane of rat renal proximal tubules and regulated by dietary Pi. Am J Physiol Renal Physiol 2009; 296: F691-699. http://dx.doi.org/10.1152/ ajprenal.90623.2008

[32] KWON CH, PARK HJ, LEE JR, KIM HK, JEON TY et al. Serpin peptidase inhibitor clade A member 1 is a biomarker of poor prognosis in gastric cancer. Brit J Cancer 2014; 111: 1993-2002. http://dx.doi.org/10.1038/bjc.2014.490

[33] Ferey JL, Brault JJ, Smith CA, WITCZAK CA Constitutive activation of CaMKKalpha signaling is sufficient but not necessary for mTORC1 activation and growth in mouse skeletal muscle. Am J Physiol Endocrinol Metab 2014; 307: E686-694. http://dx.doi.org/10.1152/ajpendo.00322.2014

[34] MOCH H, MONTIRONI R, LOPEZ-BELTRAN A, CHENG L, MISCHO A Oncotargets in different renal cancer subtypes. Curr Drug Targets 2015; 16: 125-135. http://dx.doi.org/10.2 $\underline{174 / 1389450116666150126110632}$ 